\title{
Case Reports: Add Value Beyond the Impact Factor
}

\author{
Darshana T. Shah, PhD ${ }^{1}$
}

\section{KEYWORDS}

Case Report

Author affiliations are

listed at the end of this

article.

Correspondence to:

Darshana Shah, PhD

Marshall Unviersity

Joan C. Edwards

School of Medicine

shah@marshall.edu

In this issue of the Marshall Journal of Medicine, we have published four unique case reports, which include detailed descriptions of the symptoms, diagnoses, disease courses, and treatments of patients. Case reports are a prominent form of medical communication that can be traced back to ancient Egypt. ${ }^{1}$ They promote scholarly communication and add value to the advancement of medicine as they share new discoveries and rare observations. Case reports may also introduce medical students, residents, and fellows to medical writing, offering them the opportunity to make scholarly contributions to medical literature. Good case reporting requires focus, and high-quality case reports are more likely to get accepted when authors follow reporting guidelines such as the CARE (Case Report) checklist. ${ }^{2}$ They can reveal early signals of potential benefits and harm, educate on the use of resources, provide evidence for clinical research and clinical practice guidelines, and inform medical education.

In the publishing world, case reports still rank at the bottom of evidence-based literature. Since case reports do not receive nearly as many citations as meta-analyses or randomized controlled trials ${ }^{2}$, journals have ceased or significantly limited the number of case report publications. ${ }^{3}$ However, the Marshall Journal of Medicine values case reports that contribute to the clinical evidence base and stimulate further investigations. Therefore, the Marshall Journal of Medicine editorial board welcomes the submission of high-quality case reports, which may represent significant contributions to medical literature.

\section{AUTHOR AFFILIATIONS}

1. Marshall University Joan C. Edwards School of Medicine, Huntington, West Virginia

\section{REFERENCES}

1. Nissen T, Wynn R. The history of the case report: a selective review. J R Soc Med. 2014;5(4):1-5.

2. Riley DS, MS,Kienle GS, Aronson JK, Von SchoenAngere $T$, Tugwell, Kiene $H$, Helfand $M$, Altman DG, Sox H, Werthmann PG, Moher D, Rison RA, Shamseer L, Koch CA, Sun GH, Hanaway P, Sudak 
NL, Kaszkin-Bettag M, Carpenter JE, Gagnier JJ. CARE guidelines for case report: explanation and elaboration document. J Clin Epidemiol. 2017;89:218-235.

3. Patsopoulos NA, Analatos AA, loannidis JPA. Relative citation impact of various study designs in the health sciences. JAMA. 2005;293(19):23622366.

4. Akers KG. New journals for publishing medical case reports. J Med Libr Assoc. 2016;104(2):146149. 